\title{
Trade Potential and Efficiency of the Countries Along the B\&R: Based on Trade Diversification, Concentration and Complementarity
}

\author{
Li Kexin \\ Department of International Trade, Nanjing Normal University, Nanjing, China
}

Email address:

1lkxnj@163.com

To cite this article:

Li Kexin. Trade Potential and Efficiency of the Countries Along the B\&R: Based on Trade Diversification, Concentration and Complementarity. Journal of World Economic Research. Vol. 7, No. 2, 2018, pp. 44-51. doi: 10.11648/j.jwer.20180702.11

Received: March 30, 2018; Accepted: April 23, 2018; Published: May 18, 2018

\begin{abstract}
The bilateral trade flow data in this paper is a collection of the 35 countries along "The Belt and Road" from 1995 to 2014. After getting the national trade efficiency and trade potential estimation, heterogeneous panel cointegration estimation methods (FMOLS and PDOLS) are used to analyze the influencing factors of trade efficiency and trade potential from three aspects: trade diversification, trade concentration and trade complementarity index. The lower the degree of trade diversification and the higher the degree of trade centralization are, the greater the potential of the country's trade is; the lower the degree of trade diversification and the higher the degree of trade centralization are, the more trade efficiency of the country is; for the bilateral trade volume, the higher the degree of trade complementarity between the two countries is, the greater the trade potential and trade efficiency between them is.
\end{abstract}

Keywords: Trade Potential, Trade Efficiency, Trade Diversification, Trade Concentration, Trade Complementarity

\section{Introduction}

"The Belt and Road" initiative was put forward in 2013, which has been lasting for three years. Now it is aimed at a higher level of global economic cooperation. In 2016 the global trade amounted to 32097.9 billion dollars, and the total foreign trade of the 67 countries along "The Belt and Road" was $\$ 7440.9$ billion dollars, accounting for about $23.18 \%$ of total global trade with a slight decline compared to 2015 .

Figure 1 shows the proportion of the total trade volume of the countries along "The Belt and Road" accounted for the total global trade from 2011 to 2016 was declined. This means that in the background of global trade growth decline, trade of the countries along $B \& R$ was affected. From a regional perspective, Southeast Asian trade accounting for $26.62 \%$ of the countries along the line in 2016, and it is largest followed by the Middle East and North Africa, which accounting for $18.22 \%$. The proportion of trade in Southeast Asia, Eastern Europe and West Asia are smaller, as shown in Figure 2.

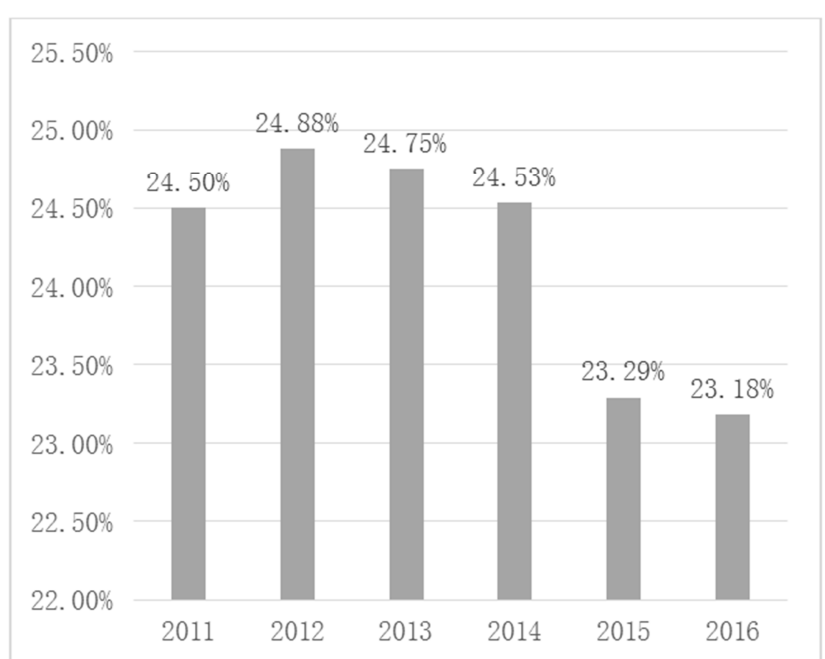

Figure 1. The countries' trade of the $B \& R$ volume accounted for the proportion of total global trade. 


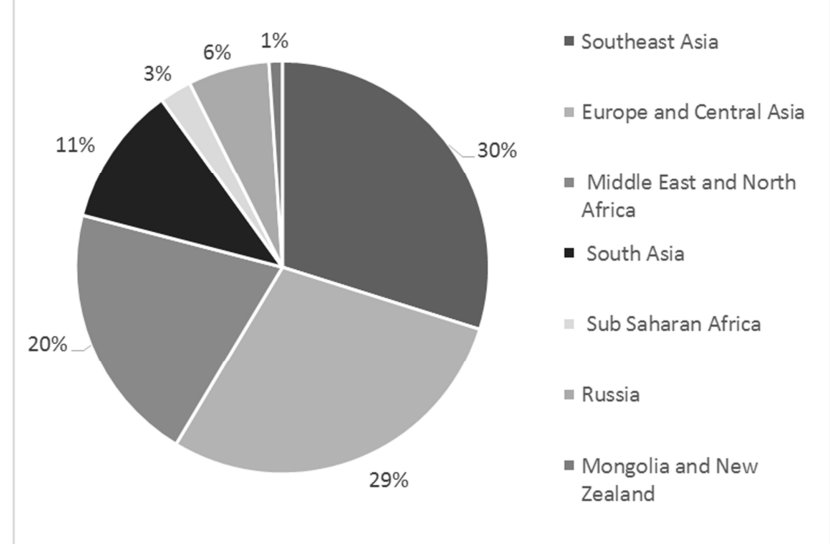

Figure 2. The trade area distribution of the countries along the $B \& R$.

Whether does the trade between the countries along The Belt and Road still have room for promotion? What are the differences of trade efficiency and trade potential between different countries and regions? How do the trade diversity, concentration and complementarity of different countries affect the efficiency and the potential of bilateral trade? To solve these problems, stochastic frontier production function model is used to measure trade potential and trade efficiency, and then analyzing the factors of trade efficiency and trade potential. When analyzing the factors, this paper introduces diversification degree, centralization degree and trade complementarity index rather than traditional trade factors, as they are more accurate to judge the characteristics of countries' trade and analyze the characteristics of bilateral trade.

The early estimation of trade potential based on the Trade Gravity Model, and then used the ordinary least square (OLS) estimator as the trade potential of bilateral trade. Baldwin (1994) analyzed the advantages and disadvantages of the European Union as an alliance, by measuring the trade potential of European countries. Nelson (2000) was also based on the gravity model and OLS, getting the actual and potential trade volumes of the EU candidate countries (Central and Eastern European countries and Cyprus) and the countries of the EU. The results showed that trade integration degree between the candidate countries and the EU was high, which meant the candidates didn't face severe pressure and market forces from the EU competition in the short to medium term. Geda (2015) attempted to examine the potential for intra-Africa trade using the gravity models with OLS methods, and the results revealed the existence of significant potential for intra-Africa trade. Mehchy (2015) used the gravity model to simulate the impact of the ongoing conflict in Syria on the potential for exports; the results showed that sanctions and the deterioration in institutional factors were expected to have reduced Syria's export potential by more than $70 \%$, which might lead to a complete collapse of the economy in the short term.

However, the problem of least squares method is that it estimates the central value of data set. According to the concept of trade potential, the calculation of trade potential needs a process of getting the upper limit rather than the central value of data set. Many methods have been put forward to solve this problem. Péridy (2010) combined the recent developments of gravity models and Arellano and Bond dynamic models, and the results unambiguously indicated that as compared to the other OECD countries, the USA suffered from a substantial trade integration deficit with MENA countries. Armstrong (2011) constructed a frontier of potential trade for trade flows from a world trade matrix of trade determinants to compare East Asian trade performance with that of South Asia. The results suggested that there was scope to lift intraregional trade among the East Asian economies but South Asia had even more unrealized potential. Chen (2017) used the fixed effects model and augmented gravity model to estimate ASEAN's export space, and the estimation showed that there was still space for ASEAN countries to further develop intraregional trade. Kalirajan (2008) proposed to estimate the trade potential by combining trade gravity model with stochastic frontier method. The stochastic frontier trade gravity model has more advantages than the traditional trade gravity model. It not only measures the effects of various variables in the trade gravity model, but also considers other man-made factors, such as the infrastructure construction and the impact of institutional reform on bilateral trade.

According to the comparative advantages theory, the sources of comparative advantages conclude not only the different endowments of the countries or regions, but also the different intensity of inputs when producing different commodities, both of which can be included in the production function. Therefore, the trade potential can also be calculated by combining the stochastic frontier method with the production function. Chen Chuanglian (2016) used the stochastic frontier method of transcendental logarithmic production function to calculate the trade potential of 85 countries in the world. The conclusion was that although the overall trade potential was increasing, the trade potential of OECD countries was larger than other countries.

\section{Model Construction and Variable Selection}

\subsection{Model Construction}

$e x_{i j t}$ represents the export from country $i$ to country $j$ in year $t$, then the production function of bilateral trade can be written as:

$$
\begin{gathered}
\ln e x_{i j t}=\alpha_{0}+\alpha_{1} \ln L_{i t}+\alpha_{2} \ln K_{i t}+\alpha_{3} \ln L_{j t}+\alpha_{4} \ln K_{j t}+ \\
\alpha_{5} t+\alpha_{6} t \ln L_{i t}+\alpha_{7} t \ln K_{i t}+\alpha_{8} t \ln L_{j t}+\alpha_{9} t \ln K_{j t}
\end{gathered}
$$

The application of the stochastic frontier production model on the export can be written as:

$$
e x_{i j t}=f(x, t)+v_{i j t}-u_{i j i}
$$

In this function, $x$ represents all kinds of factors determining the export volume, including capital and foreign direct investment. $f(x, t)$ indicates the maximum export with 
a given investment, when $v_{i j t}$ is a random error, and $u_{i j t}$ has a $\mathrm{N}\left(0, \sigma_{v}^{2}\right)$ distribution. The distribution of $u_{i j t}$ is an independent, zero truncated normal distribution, that is, $u_{i j t} \sim \mathrm{N}\left(\mathrm{m}_{i j t}, \sigma_{u}^{2}\right)$. So, the function can be written as:

$$
u_{i j t}=u_{i j} \exp (-\eta(\mathrm{t}-\mathrm{T}))
$$

$\eta$ is the temporal change of the technology inefficiency. If $\eta>0$, the rate of technical inefficiency will decrease. If $\eta<0$, the rate of technical inefficiency will increase. If $\eta=0$, the rate of technical inefficiency will be constant. The methods mentioned by Battese and Broca (1997) should be considered in order to the maximum likelihood estimation,:

$$
\sigma^{2}=\sigma_{v}^{2}+\sigma_{u}^{2}, \quad \gamma=\frac{\sigma_{u}^{2}}{\sigma_{v}^{2}+\sigma_{u}^{2}}, \quad 0<\gamma<1
$$

Therefore, the trade potential is: $g=\frac{\sqrt{\ln \widehat{e x}_{l j t}}-\ln e x_{i j t}}{\ln e x_{i j t}}$

$$
\text { The trade efficiency is: } T E_{i j t}=\exp \left(-u_{i j t}\right)
$$

After setting the model, the tests of the model are divided into two aspects. On the one hand, the rationality of the trade estimators calculated by the stochastic frontier model should be test. On the other hand, maximum likelihood estimation should be used to test whether there has a trade efficiency. The test formula is as follows:

$$
\mathrm{LR}=-2\left\{\ln \left[\frac{L\left(H_{0}\right)}{L\left(H_{1}\right)}\right]\right\}=-2\left\{\ln \left[L\left(H_{0}\right)\right]-\ln \left[L\left(H_{1}\right)\right]\right\}
$$

$H_{0}$ is the null hypothesis (there is no trade efficiency), $\ln \left[L\left(H_{0}\right)\right]$ and $\ln \left[L\left(H_{1}\right)\right]$ are the estimated values under the null hypothesis and alternative hypothesis, and the distribution of LR test statistic is mixed chi square distribution. On this basis, $\gamma$ which is the proportion of trade inefficiencies in random perturbations can be analyzed according to the function (4) and (5). If $\gamma$ is close to 0 , the gap between the actual volume of trade and the potential of trade will mainly from the uncontrollable random factors, which can be estimated by the least square method; if $\gamma$ is close to 1 , it will be better to choose a random frontier model.

\subsection{Variable Selection}

This paper collects the bilateral trade flows data of 35 countries along the Belt and Road from 1995 to 2014. The variables involved are as follows:

a. Capitals and labors. The impacts of capitals and labors on trade are mainly reflected in the supply side. The growth of production factors brings economic growth, then affecting trade, which is related to the growth mode of production factors. The calculation of capital stock should be based on the total amount of capital formation in the World Bank Database (the constant price of the dollar in 2005). According to the perpetual inventory method: $K_{t}=I_{t}+\left(1-\delta_{t}\right) K_{t-1}$. $I_{t}$ represents the investment in year $\mathrm{t}$ (capital formation), and $\delta_{t}$ represents the depreciation rate in year $t$, assuming it is $5 \% . g$ is the average growth rate of 20 years of capital formation, which can be written as $g=\ln \left(I_{2014} / I_{1995}\right) /$ 20. Labor data in this paper is from the World Bank Database.

b. Exchange rate. Influences of exchange rate on trade are generally divided into two types: the first is the devaluation of the currency, which can make the scale of domestic export increases and import decreases. The other is the appreciation of the currency and the decline of foreign exchange rate, which weakens the purchasing power of foreign currencies to domestic goods and services, thereby restraining exports and stimulating imports. In reality, the impact of exchange rate on trade will be affected by the price elasticity of import and export products, and only if the price elasticity of demand for these products is large enough, exchange rate changes can effectively affect trade. The exchange rates of this paper are exchange rate data of the countries in the World Bank Database.

c. Other common variables (distance, whether they are on the border, whether they use the same official language or whether they have colonialism). In general, longer distance between two countries leads to lower bilateral trade, because of the cost and risk in transportation. The traditional view is that if two countries border on each other, they are more likely to trade. But with the improvement of national transportation, the trade become more convenient than before, so whether border or not may be no significant parameters. Whether border is a dummy variable. Language is the supporter of culture, if two countries use the same language, that will help enhance trust between them and is conducive to business development. In addition, two countries usually choose the language that can reduce the communication cost, which means when they use the same official language, the communication cost of trade will be the lowest. Whether using the same kind of official language is also the dummy variables, using the same kind of official language is 1 . Colonization means that some countries once obtained the possession of underdeveloped region. These countries will directly affect the colonial, making them closer to the sovereign in economic, politics and culture. Even after lifting the colonial relationship, the political and cultural relationships between them are closer. The model of this paper is set as follows:

$$
\begin{gathered}
\ln e x_{i j t}=\alpha_{0}+\alpha_{1} \ln L_{i t}+\alpha_{2} \ln K_{i t}+\alpha_{3} \ln L_{i j t}+\alpha_{4} \ln K_{i j t}+\alpha_{5} t+\alpha_{6} t \ln L_{i t}+\alpha_{7} t \ln K_{i t}+\alpha_{8} t \ln L_{i j t}+\alpha_{9} t \ln K_{i j t} \\
+\alpha_{10} \mathrm{e}_{i t}+\alpha_{11} \text { dist }_{i j}+\alpha_{12} \text { contig }_{i j}+\alpha_{13} \text { cmlang }_{i j}+\alpha_{14} \text { colong }_{i j}+v_{i j t}-u_{i j t}
\end{gathered}
$$


Table 1. The specific connotation and data source of each variable.

\begin{tabular}{lll}
\hline Variables & Meaning & Unit \\
\hline ex & Export of state $i$ to state $j$ in t & Millions of dollars (at current price) \\
$L_{i t}$ & Total labor force of state $i$ in t & Millions of people \\
$K_{i t}$ & Total capital stock of state $i$ in t & Millions of dollars (at current price) \\
$L_{i i t} 1$ & The ratio of the labor force of state $i$ to state $j$ in t & \\
$K_{i j t}$ & The ratio of the capital stock of state $i$ to state $j$ in t & \\
$\mathrm{e}_{i t} 1$ & The exchange rate of currency of state $i$ to US dollar(Direct Quotation) base of World & \\
dist $_{i j}$ & The distance between the state $i$ and the state $j$ & 100 kilometers \\
contig $_{i i}$ & Whether state $i$ is bordering on state $j$ & 1 or 0 \\
cmlang $_{i j} 1$ & Whether state $i$ and state $j$ use the same official language & 1 or 0 \\
colong $_{i j} 1$ & Whether there is a colonial relationship between state $i$ and state $j$ & 1 or 0 \\
\hline
\end{tabular}

In addition, this paper analyzes the factors affecting trade potential and trade efficiency with trade diversification index, trade centralization index and trade complementarity index. The trade diversification index reveals the difference between the trade structure of the country and the world average. It can also reflect the similarity of the trade structure between countries through the comparison of trade diversification indexes. The calculation formula of trade diversification index is $S_{j}=$ $\sum_{i=1}^{n}\left|h_{i j}-h_{i}\right| / 2$, where $h_{i j}$ is the share of product $i$ in the total export or total import of state $j, h_{i}$ is the share of $i$ in the world's total exports or total imports. The value of trade diversification index ranges from 0 to 1 . The closer that this value to 1 is, the larger the gap between the export structure and the world average level is, and the more it depends on a few exports.

The index of trade centralization is an indicator of the degree of market concentration, reflecting whether a country's trade is dependent on a small number of countries. The calculation formula is $\mathrm{H}_{j}=\left(\sqrt{\sum_{i=1}^{n}\left(x_{i j} / X_{j}\right)^{2}}-\sqrt{1 / n}\right) /(1-$ $\sqrt{1 / n}$ ), and $X_{j}=\sum_{i=1}^{n} x_{i j} \cdot x_{i j}$ is the export value of product $i$ in state $j$, and $n$ is the total kinds of export products. The value of trade concentration index ranges from 0 to 1 . If it's closer to 1 , the export market will be more concentrated, and the trade will depend more on a few countries. Otherwise, the market will be more diversified.

The trade complementarity index is a measure of the consistency between the export structure of the exporter and the import structure of the importer, which reflects the complementarity of trade between the two countries. The calculation formula is $\mathrm{C}_{j k}=1-\sum_{i}\left|\mathrm{E}_{i j}-\mathrm{M}_{i k}\right| / 2 . \mathrm{E}_{i j}$ is the share of the product $i$ in total exports of country $j, \mathrm{M}_{i k}$ is the share of the product $i$ in total imports of country $\mathrm{k}$. The range of trade complementarity index is 0 to 1 , when the trade complementary index is equal to 1 , it means that import and export commodities completely complementary between these two countries. Be closer to 1 indicates that there has a smaller gap between the import and export structure of two countries, so the complementarity is higher, and the trade between them brings more benefit.

\section{Analysis of Trade Potential and Trade Efficiency}

\subsection{Estimation Results of Stochastic Frontier Model}

The results of Table 2 show that the growth of the domestic capital stocks and the labor forces have significant positive impacts on their exports. The inputs of capital and labor will significantly promote their export, and the effect of the accumulation of capital stocks on export increases significantly over time, but considering the exchanging rate, distance, whether border on each other language and other factors, the effect of labor forces decreases over time.

For different importing countries, the comparative advantages are considered. The larger the comparative advantage of domestic capital is, the smaller the export volume is. The interaction coefficient shows that the restraining effect of comparative advantage of capital will increase over time. The comparative advantage of domestic labor has no significant effect on exports. But it can still be seen from interaction coefficient that as time goes on, if a country has more advantages in labors, it will promote more in exports. These results show that "The Belt and Road" countries give priority to the export of labor-intensive products.

Table 2. Estimation results of stochastic frontier model.

\begin{tabular}{|c|c|c|}
\hline $\ln \left(e x_{i j t}\right)$ & Coef. & St.d \\
\hline \multicolumn{3}{|c|}{ Characteristics of export countries } \\
\hline Constant & $-6.375 * * *$ & 0.870 \\
\hline $\ln \left(K_{i t}\right)$ & $1.143 * * *$ & 0.028 \\
\hline $\ln \left(L_{i t}\right)$ & $0.968 * * *$ & 0.145 \\
\hline \multicolumn{3}{|c|}{ Characteristics of import countries } \\
\hline $\ln \left(K_{i j t}\right)$ & $-0.522 * * *$ & 0.019 \\
\hline $\ln \left(L_{i j t}\right) 1$ & -0.140 & 0.106 \\
\hline \multicolumn{3}{|c|}{ Time and interaction } \\
\hline$t 1$ & 0.003 & 0.008 \\
\hline$t \ln \left(K_{i t}\right) 1$ & $0.005 * * *$ & 0.0006 \\
\hline$t \ln \left(L_{i t}\right) 1$ & $-0.028 * * *$ & 0.003 \\
\hline$t \ln \left(K_{i j t}\right) 1$ & $-0.003 * * *$ & 0.0006 \\
\hline$t \ln \left(L_{i j t}\right) 1$ & $0.021 * * *$ & 0.003 \\
\hline \multicolumn{3}{|c|}{ Characteristics of bilateral relations } \\
\hline $\mathrm{e}_{i}$ & $0.712 * * *$ & 0.573 \\
\hline $\ln \left(\right.$ dist $\left._{i j}\right) 1$ & $-0.016 * * *$ & 0.017 \\
\hline contig $_{i j} 1$ & $1.051 * * *$ & 0.100 \\
\hline cmlang $_{i j} 1$ & $0.583 * * *$ & 0.101 \\
\hline colong $_{i j} 1$ & $0.609 * * *$ & 0.125 \\
\hline$u l$ & $3.746 * * *$ & 0.136 \\
\hline$\eta 1$ & $0.005 * * *$ & 0.0007 \\
\hline Log likelihood & -25137.07 & \\
\hline
\end{tabular}

The effect of exchange rate on export is significant positive, indicating that the higher the exchange rate is, the greater the export is, which is within the expectation. The distance between the exporting country and the importing country has a significant negative impact on the export, which means the 
farther the distance is, the smaller the export volume is. Whether border or not will also have a significant positive impact on the export. In addition, the common official language of the two countries and the colonial relationship between them will significantly increase the export.

In addition, according to the formula (8), $\eta$ reflects the trend of trade efficiency. If $\eta$ is greater than zero, the trade efficiency will increase. If $\eta$ is less than zero, the trade efficiency will decrease. In this model, $\eta$ is equal to 0.005 , and significantly greater than zero, indicating that the trade efficiency of the countries along "The Belt and Road " overall increases. It can be seen from the value of $u$ that there has a significant existence of trade inefficiencies.

Finally, the regression equation obtained in this paper is as follows:

$$
\begin{gathered}
\ln e x_{i j t}=-6.375+1.143 \ln K_{i t}+0.968 \ln L_{i t}+0.522 \ln L_{i j t}+-0.140 \ln K_{i j t}+0.003 t+0.005 t \ln K_{i t}-0.028 t \ln L_{i t}- \\
0.003 t \ln K_{i j t}+0.021 \ln L_{i j t}+0.712 \mathrm{e}_{i}-0.016 \text { dist }_{i j}+1.051 \text { contig } \\
i j
\end{gathered}
$$

Based on the formula (9), the trade efficiency and trade potential between the 35 countries along "The Belt and Road" can be calculated. And then the trade behavior of different countries can be compared.

\subsection{Comparison of Trade Potential in Different Areas}

The trade potential is calculated by comparing the difference between the estimated value and the actual value. In Figure 3, it shows that the volume of bilateral trade in different regions and all countries along "The Belt and Road" have a downward trend after rising in short term. But after 2011 the trade potential began to rise again. It can be seen that the level of trade potential in Southeast Asian countries was significantly lower than "The Belt and Road" overall level. The level of trade potential in West Asia and North African countries is significantly higher than the overall level, while the countries in Central Asia and Europe are basically the same as the overall level. Southeast Asian countries' trade potential is relatively low, indicating that the gaps between these countries estimate values and the actual values are small, basically in the range of $0.15-0.2$; the potential of trade in Central Asia and Europe as well as in the range of 0.15-0.2, but the average trade potential of each time point is higher than that of Southeast Asian countries. The value of the trade potential of Western Asia and North Africa fluctuates in the range of $0.2-0.25$.

To a certain extent, the different trade potential in various regions mean that the different geographical location and economic conditions of countries have different effects on trade. The trade of countries in Southeast Asia have developed fast in recent years. Their major trading partners include China, the United States, Japan, South Korea, and the members of the association of Southeast Asian nations. A large part of its economic growth comes from the export of a large number of tropical crops, labor intensive products and the development of tourism. As a important way to continuously promote the growth of GDP in Southeast Asian countries, their trade have been relatively mature, so the can transform the potential trade to the actual volume of trade well. The overall development of Central Asian and European countries is relatively better, but their trade potential is slightly lower than that of Southeast Asian countries due to their geographical location limiting their trade development. The economic development of Western Asia and North Africa is the lowest, and the economic development restrict the trade development, so these countries at low level of trade, and their trade development has the largest space to improve.

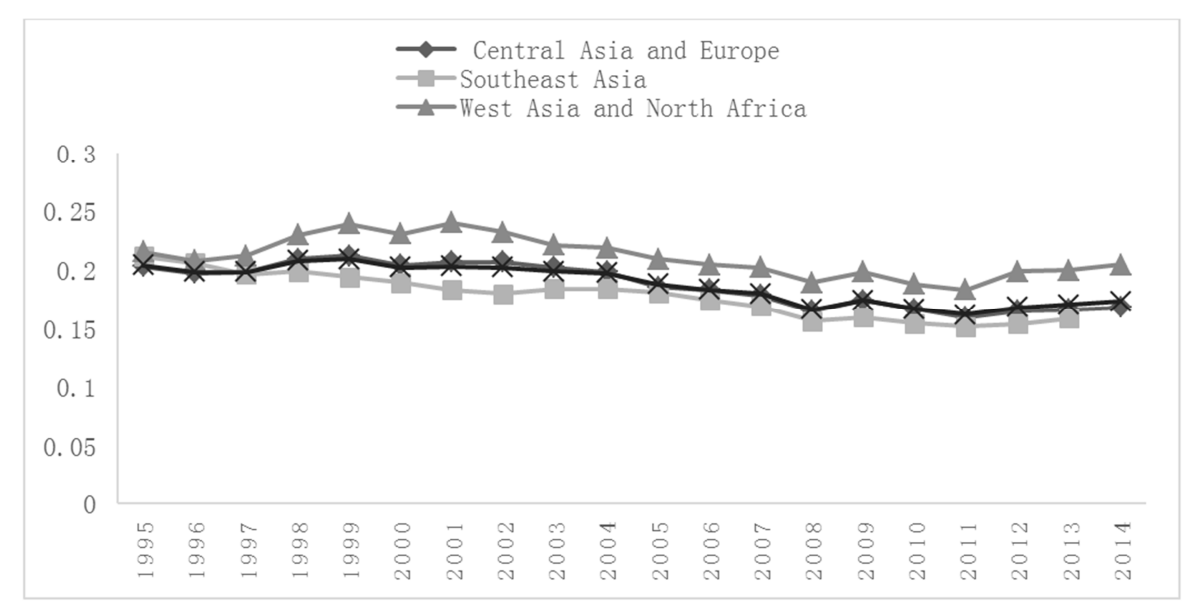

Figure 3. Comparison of trade potential in different areas.

\subsection{Comparison of Trade Efficiency in Different Areas}

$\eta>0$ have been confirmed in previous part of the paper, which means the overall level of trade efficiency of the countries along The Belt and Road is rising over time, embodied in figure 4. Among them, trade efficiency values of Southeast Asian countries and Central Asian and European countries are higher than the all the Belt and Road countries. Southeast Asian countries trade efficiency 
remains above 0.07; Central Asia and European countries trade efficiency rises from 0.06 to 0.07 ; West Asia and North Africa countries trade efficiency is the lowest, rising from 0.03 to 0.04 .

The overall trade efficiency rising means that "The Belt and Road" countries are constantly improving their exports structures, increasing trade investment and improving trade conditions to promote the trade. Southeast Asian countries have unique geographical location and convenient maritime traffic. In recent years, the strength of Chinese labor is no longer obvious, so the comparative advantage of Southeast Asian countries is prominent. Therefore, they have introduced policies to seize the opportunities to promote foreign trade through increasing cooperation with other countries. While Central Asian and European countries have high economic development but are deep inland, their trade mainly depends on land transportation, which means that these countries will rely more on trade with neighboring countries. The trade efficiency between Central Asia and Europe is also maintained at a relatively high level because of their high similarity in culture, language and institution. The lowest level of trade efficiency is West Asia and North Africa, as undeveloped economics mean that capitals and labors don't be invested adequately. Besides the economy itself and inconvenient transportation restrict the development of foreign trade, their trade partners are also mainly concentrated in the neighboring countries. However, there are unstable situations and imperfect institutions in their neighboring countries, which further constrains the efficiency of investment and export. Therefore, the trade efficiency in West Asia and North Africa is the lowest.

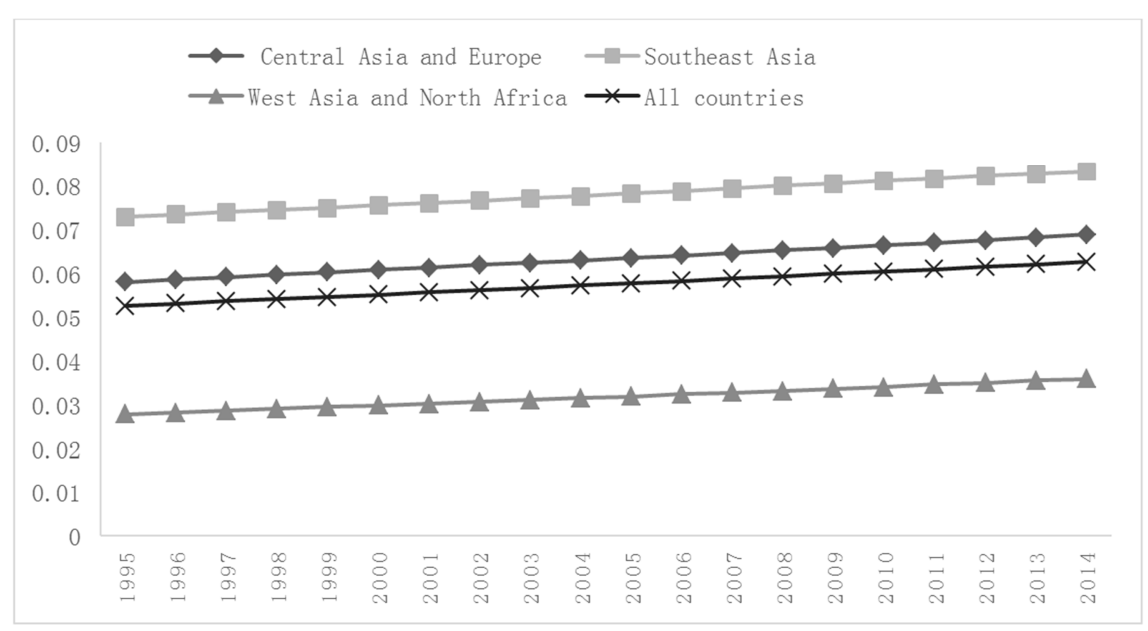

Figure 4. Comparison of trade efficiency in different areas.

\subsection{Comparison Between Trade Efficiency and Trade Potential}

In addition, Figure 5 shows the export potential of the countries along "The Belt and Road" is higher than the export trade efficiency. The trade efficiency of these countries is at a relatively low level. The export potential is decreasing year by year, while the export efficiency is increasing year by year, which means that through continuous technological innovation, the trade between countries become more efficient. But the export efficiency increased just a little, which means the countries along "The Belt and Road" still need greater promotion of the trade efficiency. The drop of trade potential reflects the fact that the gap between the actual trade volume and the expected maximum trade volume is decreasing.

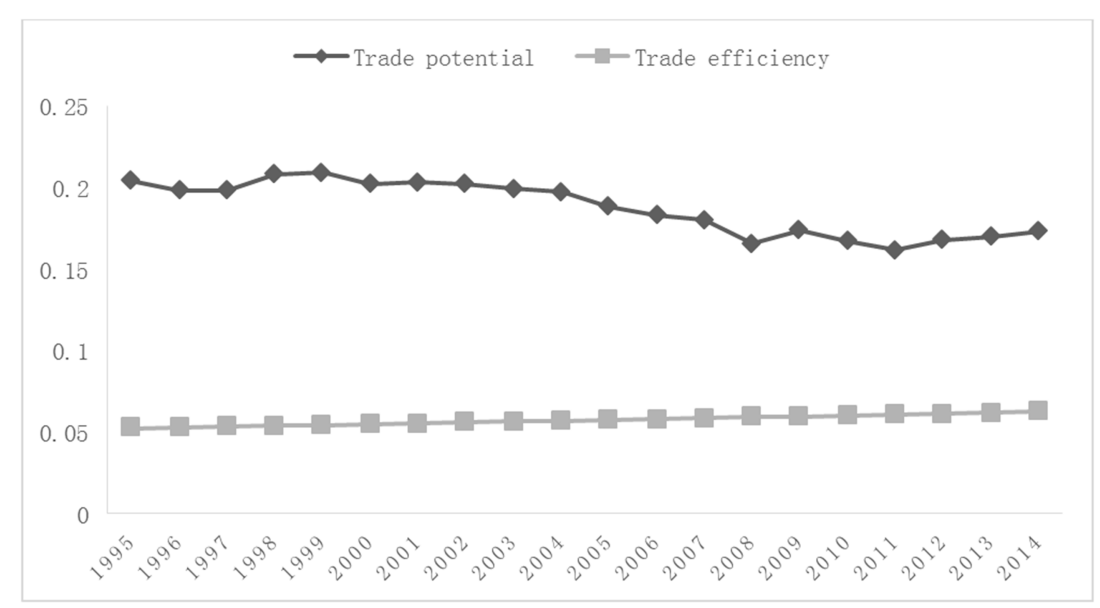

Figure 5. Comparison between trade efficiency and trade potential. 


\section{Factor Analysis for the Trade Potential and Efficiency}

The impact of trade diversification, concentration and complementarity on trade potential and trade efficiency is then analyzed. In this paper, heterogeneous panel FMOLS and panel DOLS proposed by Kao and Chiang (1999) are used to analyze, and the software used is Gauss 9.0. The regression results are shown in Table 3 .

As shown in Table 3 (1), the impacts of the diversification index on the trade potential in the two methods are different. The coefficients in FMOLS are positive and significant in the $1 \%$ level, but in the PDOLS model considering the concentration index and complementary index, the coefficient of trade diversification index is significantly negative at the $1 \%$ level. That is to say the higher the degree of diversification of trade is, the lower the trade potential is. According to the theory of comparative advantage, the country will concentrate on producing products with comparative advantages to exchange for low-cost impors. In this early stage of trade, diversification is low, because exports are concentrated on a certain category of products. And in this stage with obvious comparative advantages, they still have the potential to further expand trade through integrating resources, technological innovation and productivity improvement.

For the impact of trade centralization on trade potential, the results of the two methods are significantly positive. It means the higher the trade concentration index is, the greater the trade potential of the country is. When a country's trade mainly concentrat on a few countries, the trade development with these countries will eventually reach a stable period after a rapid growth. If these countries turn attention to other trading partners, they will greatly promote trade by finding new comparative advantages with new trading partners, then the trade potential will be aroused. Therefore, for countries with higher trade concentration index, they have greater scope of other trading partners, and the trade potential of the country is greater.

The trade complementarity index obtained by FMOLS has a significant positive impact on trade potential. It shows that the higher the trade complementation index of the two sides is, the greater the trade potential of the two sides is. The trade complementation index obtained by PDOLS method has a negative impact on trade potential, but not significant. In sum, the stronger the trade complementarity between the two countries is, the more obvious the comparative advantages between them are, and they will have bigger trade promotion space then trading with other countries.

Table 3. Estimates of the impact of diversification, centralization and trade complementarity on trade potential and efficiency.

\begin{tabular}{|c|c|c|c|c|c|c|}
\hline & FMOLS & & & PDOLS & & \\
\hline \multicolumn{7}{|l|}{ (1) Trade potential } \\
\hline Diversification index & $\begin{array}{l}0.3285 * * * \\
(56.8434)\end{array}$ & $\begin{array}{l}0.2373 * * * \\
(20.5852)\end{array}$ & $\begin{array}{l}0.1142 * * * \\
(14.3815)\end{array}$ & $\begin{array}{l}0.0551 * * * \\
(7.9441)\end{array}$ & $\begin{array}{l}-0.038 * * * \\
(-4.0818)\end{array}$ & $\begin{array}{l}-0.0245 * * * \\
(-2.5691)\end{array}$ \\
\hline Centralization index & & $\begin{array}{l}0.1580 * * * \\
(23.7152)\end{array}$ & $\begin{array}{l}0.1068 * * * \\
(13.7062)\end{array}$ & & $\begin{array}{l}0.0361 * * * \\
(4.5159)\end{array}$ & $\begin{array}{l}0.0203^{* * *} \\
(2.1669)\end{array}$ \\
\hline $\begin{array}{l}\text { Complementarity index } \\
\text { (2) Trade efficiency }\end{array}$ & & & $\begin{array}{l}0.2046 * * * \\
(27.0675)\end{array}$ & & & $\begin{array}{l}-0.0014 \\
(-0.1565)\end{array}$ \\
\hline Diversification index & $\begin{array}{l}0.1019 * * * \\
(17.97)\end{array}$ & $\begin{array}{l}0.0463 * * * \\
(6.10)\end{array}$ & $\begin{array}{l}0.0664 * * * \\
(8.60)\end{array}$ & $\begin{array}{l}-0.125^{* * *} \\
(-18.37)\end{array}$ & $\begin{array}{l}0.0356 * * * \\
(3.91)\end{array}$ & $\begin{array}{l}0.0269 * * * \\
(3.05)\end{array}$ \\
\hline Centralization index & & $\begin{array}{l}0.0750 * * * \\
(11.52)\end{array}$ & $\begin{array}{l}0.0227 * * * \\
(3.00)\end{array}$ & & $\begin{array}{l}-0.0515^{* * *} \\
(-6.52)\end{array}$ & $\begin{array}{l}-0.0229 * * * \\
(-2.48)\end{array}$ \\
\hline Complementarity index & & & $\begin{array}{l}0.0481 * * * \\
(6.55)\end{array}$ & & & $\begin{array}{l}-0.0096 \\
(-1.06)\end{array}$ \\
\hline
\end{tabular}

Note:***,*** respectively indicated that the statistical level of $10 \%, 5 \%$ and $1 \%$ was significant, and the parentheses were $t$ test values.

From table 3 (2), the results show that the impact of trade diversification index on trade efficiency is significantly positive in $1 \%$ levels of two methods, indicating that the higher the diversification degree of a country's trade products is, the higher the trade efficiency of the country is. More kinds of products in trade means that the trade develops better. It also means the countries have more developed economic, better infrastructure construction and more sound policies, so the trade efficiency of these countries is even higher.

Effects of trade concentration index on trade efficiency are different in FMOLS and PDOLS method. In the FMOLS method, the coefficients of diversification index are significantly positive. In PDOLS, after adding centralization index and trade complementarity index, the coefficient of diversification index is significantly negative, indicating that the higher the concentration of a country's trade is, the lower the trade efficiency of the country is. A country will always increase its input to promote trade, but when trading partners are concentrated on a few countries, the market size will be limited and the products that these markets can accept will also be limited. Therefore, even if the trade investment increases, the trade efficiency is lower in these countries.

In FMOLS, the coefficients of trade complementarity index are significantly positive at the level of $1 \%$, indicating that the higher the degree of trade complementarity between two countries is, the greater trade efficiency they have. However, in PDOLS, the coefficients of trade complementarity index are negative, but not significant. It means that the higher the trade complementarity of the two countries is, the greater the trade efficiency of they have. If two sides of trade have more 
obvious comparative advantages, their investment in trade will be more effectively transformed into the trade products between them.

\section{Conclusion}

This paper selects the bilateral trade data of 35 countries along "The Belt and Road" from 1995 to 2014 to calculate the trade potential and trade efficiency. On the basis of these, the factors affecting trade potential and trade efficiency are analyzed by introducing trade concentration index, trade diversification index and trade complementarity index.

First of all, based on stochastic frontier regression analysis, labor and capital coefficient tests results indicate that the domestic capital investments will have positive effect on export, and the positive effect will be enhanced over time. Their input of labors will also have positive effect on export, however, the positive effect will become weaker over time. Their comparative advantages in capital will inhibit exports, and the inhibitory effect will increase as time goes on, and their comparative advantage in labor will promote exports.

Secondly, after measuring the trade potential and trade efficiency, there are two conclusions. On the one hand, the trade potential of the countries along "The Belt and Road" decreased year by year until 2011. After 2011, there has been a rebound. It shows that in recent years, countries have begun to realize the problems in their exports, and they promote their export potential through adjusting their economic structure and increasing investment opportunities. In addition, countries in Western Asia and North Africa have the biggest potential for trade, followed by Central Asia and European countries, and the last is the countries in Southeast Asia. On the other hand, the trade efficiency of the countries along "The Belt and Road" increased year by year. It shows that continuous importing of high technology and equipment, improvement of market environment and economic development result in the improvement of trade efficiency. In terms of regional distribution, trade efficiency is the opposite. Trade efficiency is the highest in Southeast Asian countries, followed by Central Asia and European countries, and finally the West Asian and North African countries. Their trade efficiency is much lower than the former two.

Finally, the analysis of the factors of trade potential and trade efficiency for the countries along "The Belt and Road" was based on heterogeneous panel cointegration. The results show that countries with low degree of diversification of trade products and high degree of concentration of trade market have greater trade potential. The government can increase the types and adjust the structure of export products by encouraging technological innovation. Besides, it can also bridge the gap between the actual trade volume and expected trade volume by strengthening the trade relationships and cooperation with other countries. The countries with low degree of diversification of trade products and high degree of concentration of trade market have more efficient trade. By reducing the dependence of domestic trade on a small number of products and trading partners, improving trade environment and actively exploring new trade markets, the countries can enhance the ability of exporting and improve the efficiency of export trade. As for bilateral trade, the higher the degree of trade complementarity between the two countries is, the greater the trade potential and trade efficiency between the two countries is. This shows that even for different trading partners, the country still needs to constantly explore its comparative advantages and competitive advantages, making the development of export trade more sustainable.

\section{References}

[1] Armstrong S P, Drysdale P, Kalirajan K. Asian Trade Structures and Trade Potential: An Initial Analysis of South and East Asian Trade [J]. Eaber Working Papers, 2011, 35(7):644-653.

[2] Baldwin R E. Towards an Integrated Europe [J]. International Affairs, 1994, 70(4):806.

[3] Battese G E, Broca S S. Functional Forms of Stochastic Frontier Production Functions and Models for Technical Inefficiency Effects: A Comparative Study for Wheat Farmers in Pakistan [J]. Journal of Productivity Analysis, 1997, 8(4):395-414

[4] Battese G E, Corra G S. Estimation of a Production Frontier Model: With Application to the Pastoral Zone of Eastern Australia [J]. Australian Journal of Agricultural \& Resource Economics, 1977, 21(3):169-179.

[5] Chen L, Lombaerde P D, Cuyvers L. Markets Matter: The Potential of Intra-Regional Trade in ASEAN and Its Implications for Asian Regionalism [J]. Asian Economic Papers, 2017, 16(2):1-19.

[6] Chuanglian Chen. Factors of Global trade efficiency and trade potential and influence analysis [J]. International Trade Issues, 2016, (07): 27-39.

[7] Geda A, Seid E H. The potential for internal trade and regional integration in Africa [J]. Journal of African Trade, 2015, 2(1-2):19-50.

[8] K. Kalirajan. Stochastic varying coefficients gravity model: An application in trade analysis [J]. Journal of Applied Statistics, 1999, 26(2):185-193.

[9] Kao C, Chiang M H. On the estimation and inference of a cointegrated regression in panel data [J]. Advances in Econometrics, 1999, 15(1):109--141.

[10] Mehchy Z, Nasser R, Schiffbauer M. Trade determinants and potential of Syria: using a gravity model 'with an estimation of the Syrian crisis' impact on exports' [J]. Middle East Development Journal, 2015, 7(2):226-251.

[11] Nilsson L. Trade integration and the EU economic membership criteria $[\mathrm{J}]$. European Journal of Political Economy, 2000, 16(4):807-827.

[12] Péridy N. Towards a New Trade Policy Between the USA and Middle-East Countries: Estimating Trade Resistance and Export Potential [J]. World Economy, 2010, 28(4):491-518.

[13] Rahman M M. Australia's global trade potential: evidence from the gravity model analysis $[\mathrm{J}]$. International Journal of Business Research, 2010, 10(:2). 